\title{
Schuurs-Hoeijmakers Syndrome
}

National Cancer Institute

\section{Source}

National Cancer Institute. Schuurs-Hoeijmakers Syndrome. NCI Thesaurus. Code C150555.

An autosomal dominant condition caused by mutation(s) in the PACS1 gene, encoding phosphofurin acidic cluster sorting protein 1. It is characterized by intellectual developmental delay, craniofacial abnormalities, as well as other variable congenital abnormalities. 